\title{
El teatro de Elena Garro: Evasión e llusión
}

A pesar de ser casi desconocida fuera de su país, Elena Garro es cana. Participa plenamente del concepto del teatro como comunicación poética, ilógica, y a pesar de las diferencias de técnicas y contenidos, también sería posible colocarla dentro del movimiento del llamado "teatro del absurdo". No obstante la vigorosa variedad temática y técnica de su labor, consideramos que el teatro de Elena Garro demuestra una marcada preferencia por el tema de las relaciones entre diversos aspectos de la realidad y aun entre diversas realidades. Sus personajes oscilan entre realidad e ilusión, y este vaivén alucinado se refleja en el centelleante espejo de ilusiones por el que pasan. A base, frecuentemente, de elementos folklóricos, construye un mundo en el cual desaparecen las fronteras entre la realidad tal y como la percibimos diariamente; nos da así otro mundo, quizás ilusorio, pero acaso también más real en lo que toca a la verdad anímica del hombre.

Su obra es breve: el volumen Un bogar sólido (1958) en el cual se reúnen seis obras en un acto, más dos publicadas en la revista $L a$ Palabra y el Hombre. La que otorga su título a la colección, Un bogar sólido, es, en cierto sentido, la más rara de todas. Al alzarse el telón, vemos el "Interior de un cuarto pequeño, con los muros y el techo de piedra. No hay ventanas ni puertas. A la izquierda, empotradas en el muro y también de piedra, unas literas". Para subrayar esta sorprendente semejanza con una catacumba o algo parecido, hablan los personajes de algún hueso perdido, de "nostalgia de catástrofes"." Visten de diversas épocas, y dentro de los estrafalarios parentescos, Gertrudis, de

I Un bogar sólido, Xalapa, Ver., Universidad Veracruzana, Ficción-5, 1958, p. 13.

2 P. 14. 
cuarenta años y vestida al estilo de II930, es sobrina de la niña Catita, de cinco años. Nos damos cuenta de estar presenciando lo que pasa dentro de la fosa común del camposanto familiar de una familia provinciana. El descuido y, en algunos casos, la prisa por enterrar a los difuntos, ha provocado ciertas dificultades: Mamá Jesusita no se atreve a salir de su litera, dado que a los ochenta años la enterraron en camisón, y rezonga en su rincón "... acostada por sécula seculórum .. " 3 A don Clemente, medio olvidadizo, siempre se le extravía algún hueso.

Hasta aquí, la obra, por extraña que parezca, no deja de ser divertida, pero de repente surgen elementos menos humorísticos. Llega un nuevo morador al domicilio:

Empieza el descenso de Lidia, suspendida con cuerdas... Viene tiesa, con un traje blanco, los brazos cruzados al pecho.

Los dedos en cruz, y la cabeza inclinada. Los ojos cerrados. ${ }^{4}$

De aqui en adelante, las cosas toman un giro grotesco: se ha abierto la puerta a una muerte menos benévola. Muni, suicida, está condenado a llevar el rostro azul producido por el cianuro, y los recuerdos de un flirteo entre Vicente, de veintitrés años, y Jesusita, de ochenta, provocan calosfríos. El humorismo se ha vuelto pavor.

Este horror queda subrayado cuando comparamos las razones del suicidio de Muni con el comportamiento de los demás.

¿No has visto a los perros callejeros caminar y caminar banquetas, buscando huesos en las carnicerías llenas de moscas, y el carnicero, con los dedos remojados en sangre a fuerza de destazar? Pues yo ya no quería caminar banquetas atroces buscando entre la sangre un hueso, ni ver las esquinas, apoyo de borrachos, meadero de perros. Yo quería una ciudad alegre, llena de soles y lunas. Una ciudad sólida, como la casa que tuvimos de niños, con un sol en cada puerta, una luna para cada ventana y estrellas errantes en los cuartos. ${ }^{5}$

Frente a esta angustia, compartida por Muni y Lidia, los atros siguen dentro de la muerte tal y como siguieron dentro de la vida. No ha habido cambio alguno más allá del cambio de hogar, y este nuevo es, en lo

3 P. 23.

4 P. 22.

5 P. 27-28. 
fundamental, igual al de antes. Sigue rezongando Mamá Jesusita, Clemente es igual de aburrido, Vicente no deja de ser medio calavera, y la niña Catita se roba los huesos para jugar con ellos a banda militar.

Al final, descubrimos que los difuntos tienen la capacidad-o la fatalidad, no está claro- de mezclarse con todos los elementos que componen el mundo, desde el viento a los "dedos de la Virgen bordando. ..",6 pasando por el mismo gusano que entra por la boca de la calavera. Como dice Clemente,

Después de haber aprendido a ser todas las cosas, aparecerá la lanza de San Miguel, centro del universo, y a su luz surgirán las huestes divinas de los ángeles y entraremos en el orden celestial.?

Tras lo cual desaparecen uno por uno los diversos personajes, después de haber declarado cada cual en qué cosa piensa convertirse esta vez. Resulta dudoso que la autora quiera que tomemos esto en serio, ya que Muni, al desaparecer, dice: ¿"Oyen? Aúlla un perro. ¡Ah, melancolia!'s Si se tratara de una fusión final con el orden celestial, estaría menos acongojado. Vicente quiere ser nada menos el viento "... que corre por las calles nuevas para mi uniforme de oficial y levanta las faldas de las hermosas desconocidas ... ¡ Ah frescura!" 9 Más bien nos parece la clave de la obra las palabras de Lidia: “Un hogar sólido! ¡Eso soy yo! ¡Las losas de mi tumba!” 10 Aun después de la muerte, cada cual busca la ilusión que le sostenía mientras vivía o la necesidad que le atribulaba, pero el único hogar sólido que nos queda es meternos en la fosa. Aun así no encontraremos lo que buscamos; el ejemplo de estos muertos-muertos en vida, vivos en la muerte- nos indica que aun de haber otra vida, sería igual a ésta, vaga, evasiva, siempre escurriéndosenos de entre los dedos.

En Los pilares de Doña Blanca estamos frente a una acción totalmente irreal, antirrealista, fábula poética de la dama Blanca, su caballero Rubí, los Cuatro Caballeros rendidos de amor, que la acechan sin esperanzas, de manera ideal, y el Caballero Alazán, que viene a derribar el castillo y destruir a sus habitantes. Consiste la obra en la repetición del

6 P. 32.

7 P. 31 .

8 P. 33

9 P. 33.

10 P. 34 . 
movimiento, casi de ballet, entre Blanca y los Caballeros, quienes le ofrecen el cotazón cada uno en su turno. El movimiento con el Caballero Alazán tiene la diferencia de que éste no pierde tiempo en miramientos, sino que procede a asolar el castillo. Hecho esto, la torre cae artuinada, y no quedan de Rubí y Blanca más que su ropa y los fragmentos de un espejo roto, que el Caballero Alazán acaricia y guarda en el pecho.

Si buscamos aquí moralejas o mensajes, menudo chasco nos llevamos. Más bien funciona la obra en el nivel del sueño, lleno de espejeantes sugerencias. Blanca es coqueta consumada; mientras grita a Rubí que ya va adentro, salta encima de la muralla para buscar horizontes. Coquetea de manera llamativa con los diversos caballeros, coleccionando corazones de diversos tipos. Pero el Caballero Alazán, no contento con rendir homenaje desde afuera, golpea hasta derribar la torre, con resultados desastrosos. Hay claros indicios de la naturaleza sexual de esta materia. Rubí tiene cabeza de caballo, y el Caballeto Alazán, además de ser caballo también, lleva lanza en la mano. Todo lo dicho nos lleva a sospechar que Los pilares de Doña Blanca sea una versión poetizada del encuentro de una niña coqueta con un señor impetuoso, un señor que no se contenta con flirteos. En este sentido, representa la ilusión destruida cuando se funde con la realidad exterior. Pero la ilusión no puede desaparecer del todo; fabricamos nuevas ilusiones sobre los escombros de las viejas, y el Caballero Alazán guarda la paloma que aparece sobre los fragmentos del espejo.

Mucho más asequible es $E l$ rey mago. Felipe Ramos, encarcelado por haber matado a otro en un crimen pasional, desde el balcón enrejado de la cárcel espera que venga a pasearse Rosa, la responsable. Muy hombre, muy macho, se entretiene mariposeando con varias muchachas del pueblo y jactándose de la "honradez" de su crimen. Tan metido está en su propio asunto que no le hace caso al niño Cándido Morales cuando éste, aparentemente en broma, le ofrece hacerle rey. Hasta le pasa la estupefacción al ver que el niño, aburrido y molesto, convierte en plata un salivazo macho del preso. Sólo al final, cuando tanto el público como Felipe quedan pasmados al ver al niño alejarse volando en su caballo de palo, se da cuenta Felipe del significado de lo que le acaba de pasar, y cuando por fin llega Rosa, le dice sencillamente, "Pues alli quédate, Rosa. Quédate siete años, esperando a que yo baje"."11 No pudo reconocer el ideal, la ilusión, cuando le salió al paso, ni supo aprovecharse de algo

11 P. 77. 
mejor cuando se lo ofreció el niño. Ahora se fue éste, y la deprimente realidad le llega a Felipe en toda su escabrosa tristeza, despojada aún de la pobre ilusión de su fechoría. Resulta significativo que el carcelero haga hincapié en estar él también encarcelado. Estamos encarcelados todos, y cuando dejamos que se nos escape la ilusión, que es lo único capaz de conferir significado a la pobre realidad que vivimos, no nos queda sino esperar, como Felipe Ramos, el que pudo haber sido rey mago, siete años —o toda una vida.

En Andarse por las ramas vemos la evasión de una realidad espantosa por fea. Titina, condenada a la vida conyugal con el glotón y prosaico Don Fernando de las Siete y Cinco, que así se llama porque a las 7.05 en punto hay que comer, tiene que sufrir que éste aplaste todo asomo de poesia, de ensueño y belleza. Para él, la luna es el pecado mortal, y hay que impedir a toda costa que se mezcle con las cosas decentes, como el plato de lentejas. Cuando la tentativa final de escaparse con el Lagartito da como único resultado el descubrimiento de que éste, debajo de su superficie romántica, es tan prosaico como el otro, se refugia Titina inevitablemente y para siempre en las ramas, frente a un Don Fernando quien pasa cantando coplas alusivas y un Lagartito que prefiere las ventajas inmediatas de una señora dispuesta a aventuras, a las más poéticas de una señora Titina a quien le gusta andarse por las ramas. Para Titina, incapaz de vivir dedicada a "lo principal", la vida cotidiana, el dicho popular se ha convertido en triste realidad. Allá en su arbolito se queda, aislada de un mundo impenetrable al valor de la ilusión.

Acaso sea ésta la más feliz de la colección en términos teatrales. La estilización del dicho, manifiesta cuando Don Fernando se dirige a la silla vacía mientras está Titina subida al árbol, se plasma en el momento cuando Titina dibuja con un pedazo de gis, una casa con chimenea, humo y puerta, por la cual sale. La preocupación temática de Elena Garro encuentra expresión técnica capaz de transmitirla plenamente, y el resultado es una joya del teatro poético.

Menos lograda, en cambio, es Ventura Allende, obra de difícil comprensión. No se trata de comprensión lógica, claro está, pero la leyenda de Circe que le sirve de base al drama está tan oscurecida que la comunicación antiverbal, directa, que necesita este tipo de obra también se oscurece. El asunto es el siguiente: el campesino Ventura Allende anda malhumorado por la ladera de un monte cuando, tentado por la posibilidad de agarrar algunos miembros de una borregada y una caba- 
llada que salen galopando por una grieta, se encuentra con un puerco que le habla. Vencido su miedo por la descripción del puerco del festín que le ofrece, entra gozosamente Ventura en la orgía de gula, para convertirse al final en otro borrego.

Resulta difícil desentrañar los posibles signifıcados de esta obra, pero obviamente sobresale uno: la sátira de cierto tipo de político. Al intentar convencerle a Ventura, dice lo siguiente el puerco:

Yo quiero llevarte a un hermoso festin. iQuiero invitarte a la boda más lucida, que jamás hayas visto! ¿Quiero devolverte la fe en las bondades del mundo y sus placeres! Eres un hombre sencillo, que no ha visto sino el lado raquítico de la vida. ¡La labor de un buen mexicano es compartir con sus conciudadanos los beneficios que nos ofrece este gran país, cornucopia de la abundancia! 12

Consta que poder convertir la sencilla frase inicial en la fastuosa retórica final es triunfo acostumbrado de la politiquería barata. Mientras más avanza la obra, más retórico es el puerco y mayor la semejanza de sus parlamentos con la verborrea del político profesional. Cuando Ventura Allende se convierte al final en borrego, es resultado directo de haber sido hipnotizado por la palabrería del puerco. $\mathrm{Ni}$ es casualidad que sea puerco el que hechiza, y no los hechizados, como en la leyenda clásica. No sabemos hasta qué punto sea ésta la intención de la autora, pero después de repetidas lecturas la obra nos brinda más que nada una descarnada sátira de los políticos venales y los que se dejan embaucar por ellos. Ilusión, también, ésta de creer en las palabras en vez de los hechos, pero ilusión que en vez de enriquecer la vida o brindarnos una oportunidad de escaparnos de ella cuando se hace insoportable, nos la roba.

De delicado sentido poético es El encanto, tendajón mixto, obrita en la cual las dos realidades tangenciales vuelven a tocarse. Tres paisanos, Juventino Juárez, Anselmo Duque y Ramiro Rosas, se sobresaltan al escuchar una voz de mujer en el lugar más polvoriento y reseco del desierto. Al dejarse ver, resulta ser la dueña de la tienda del título, hermosa mujer de "suntuoso pelo negro suelto hasta las rodillas". ${ }^{13}$ El único que se atreve a beber es el joven Anselmo, $\mathrm{y}$ al instante desaparecen tienda, Anselmo y mujer. Al volver los otros dos

12 p. 109.

13 P. 134. 
al año siguiente, reaparecen los desaparecidos como si hubieran pasado nada más unos segundos. Pero Anselmo es resistente a las plegarias de sus amigos, y vuelve a desaparecer abrazado a la mujer. Termina la obra con el grito amenazador de Juventino. "iAquí vendremos, Anselmo Duque, los tres de mayo, y acabaremos con "El Encanto, Tendajón Mixto"! 14

En esta obra encontramos una de las expresiones más claras de esta preocupación de Elena Garro. La confrontación entre la ilusión y los que, incapaces de entenderla, la quieren destruir, se plasma en forma de la Mujer y los dos amigos de Anselmo. Cuando Juventino grita, “No se dejen embriagar por el engaño!", 15 replica la Mujer que "Hay que vivir embriagados, mirando las embriagadoras fuentes, los pájaros, y los ojos de la mujer". ${ }^{16}$ Anselmo Duque vive ya "... en otro tiempo ... el tiempo de los pájaros, las fuentes y la luz".17 Pero mientras Anselmo vive su realidad poética, afuera truenan sus amenazas los que, endurecidos por lo cotidiano, son incapaces de percibir una realidad superior.

La mudanza, publicada en La Palabra y el Hombre, 18 presenta dentro del más descarnado realismo, la pérdida de la ilusión. A los sesenta y siete años, Lola descubre que por una confabulación de parientes, tendrá que mudarse a otra casa, donde ya no será la señorita Lola sino la vieja cuñada molesta. En un día ve desaparecer los muebles, las fotografías y los recuerdos de toda una vida. Peor, ve desaparecer la ilusión de conservar todavía algún eco de estilo, de nobleza, $y$, desesperada, se ahorca con la chalina. La obra es distinta de las demás por el realismo absoluto, compuesto de sirvientas chismosas, parientes traidores y la imperiosa necesidad económica. La ilusión de Lola la vemos a través de su ausencia, y es esta ausencia, simbolizada por la destrucción de retratos y la venta de libros, que hace inteligible su horror y su suicidio.

La señora en su balcón muestra el progresivo abandono del mundo que a Clara le ha conducido a la absoluta soledad a los cincuenta años. Sentada en su balcón, revive en la memoria momentos claves, como el primer encuentro, a los ocho años, con el profesor que se empeñaba en que el mundo de poesía y ensueño hubiera muerto. Vemos al novio

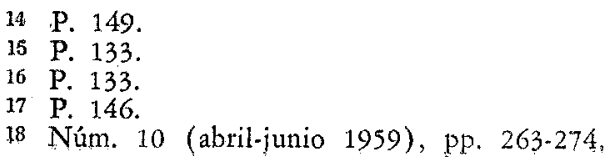


a quien plantó a los veinte porque lo que a él más le importaba era que las cosas estuvieran en orden: "Clara, éste es el amor, dame tu mano para meterte un anillo, y buscar un departamento para comer sopa y vivir con mi sueldo, si tu familia y la mía están de acuerdo". ${ }^{19}$ Y a los cuarenta años, casada con Julio, Clara ve toda la vida como viaje maravilloso.

Las calles cambian de hora en hora. Nunca son la misma calle. ¿No te has fijado? iA que nunca llegas a la misma oficina, por la misma calle! Yo quisiera ser tú, para ir a trabajar en la mañana y cruzar la ciudad a la hora en que la cruzan ustedes los que hacen el mundo. ${ }^{20}$

Pero Julio no ha visto nunca la ciudad encantada.

No digas tonterías. ¿Cómo va a ser maravilloso ir a una oficina llena de estúpidos, por unas calles también estúpidas $\mathrm{e}$ iguales? 21

Y cuando Clara le recuerda a Nínive, la ciudad mitológica, símbolo de todas sus ansias de encontrar la poesía, contesta el marido:

El amor no existe. Tampoco existe Nínive. Existe sólo un mundo que trabaja, que va, que viene, que gana dinero, que usa reloj, que cuenta los minutos y los centavos y que muere solo y acaba podrido en un agujero, con una piedra encima que lleva el nombre del desdichado. Lo demás, lo demás son tonterías. ${ }^{22}$

$Y$ ahora, a los cincuenta años, repasa Clara todas sus tentativas inútiles de fugarse del maloliente y prosaico mundo que la rodea, y opta por la fuga final: el suicidio.

Hemos visto cómo, a través de estas obras cortas, Elena Garro reitera su predilección por la relación entre una realidad prosaica, mortal, y otra realidad superior, que es la única capaz de hacer llevadera la existencia. Hemos visto también cómo esta realidad superior, esta ilusión, se les escapa a casi todos sus personajes, dejándoles frente a una existen-

19 La Palabia y el Hombre, 11 (julio-septiembre 1959), p. 441.

20. Pp. 441-442.

21 P. 442.

22 p. 443 . 
cia que no parece tener más remedio que el cianuro o el salto desde el balcón. Pero si bien nos fijamos, vemos que aun los personajes que alcanzan la ilusión han tenido que sacrificarse o la ven destruida por la embestida de los que se quedan afuera. Nos deja Elena Garro ante una encrucijada falsa, aparente nada más, ya que los dos caminos nos conducen al fracaso, abatidos por la aplastante realidad exterior que es suerte humana tener que vivir. Para comunicarnos este mensaje amargo, emplea las técnicas teatrales más diversas, desde el realismo - espejo de lo fatal que nos agobia- hasta la estilización más ilusoria - espejo de un espejo.

Rutger's University

Frank DAUSter 
